\title{
APLIKASI SISTEM PENUNJANG KEPUTUSAN PENINGKATAN QUALITY CHECK PADA PT. PAS
}

\author{
Saiful Bahri \\ Program Studi Teknik Informatika, Fakultas Teknik dan Ilmu Komputer, \\ Universitas Indraprasta PGRI \\ Jalan Raya Tengah No 80, Kelurahan Gedong, Pasar Rebo, Jakarta Timur \\ bahrisaifu1285@gmail.com
}

\begin{abstract}
Abstrak
Quality Control adalah proses pengecekan (observasi) yang dilakukan oleh suatu perusahaan untuk memastikan kualitas produk sesuai dengan standar yang telah ditetapkan. Salah satu kegiatan dari upaya pemastiaan mutu adalah inspeksi. Tujuan dari inspeksi tersebut adalah untuk mengetahui apakah produk sesuai dengan spesifikasi yang ditentukan. Tujuan penelitian adalah untuk membuat suatu perancangan aplikasi sistem penunjang keputusan peningkatan Quality Check pada PT.PAS dengan metode Acceptance Sampling. Acceptance Sampling merupakan metode penentuan penerimaan atau penolakan lot yang diamati menggunakan metode Military Standart 105E, serta mendeskripsikan hasil uji coba aplikasi sistem Quality Check. Metode penelitian yang digunakan dalam perancangan aplikasi sistem ini adalah metode penelitian dan pengembangan (research and develpoment. Tujuan pembuatan aplikasi ini yaitu membuat sistem pengecekan kualitas yang terkomputerisasi dan sebagai sistem penunjang keputusan yang dapat meningkatkan pengambilan keputusan tentang kualitas produk secara cepat dan akurat,diantaranya akan mengalami peningkatan dalam menangani proses seluruh data dibandingkan dengan manual. Pengolahan data pengecekan akan lebih efektif, serta keamanan terhadap data lebih terjamin. Proses dalam pembuatan laporan dapat dilakukan dengan cepat, tepat dan akurat. Memudahkan admin untuk memantau dan mengontrol data yang ada dalam database.
\end{abstract}

Kata Kunci: Sistem Penunjang Keputusan, Quality Check,MIL STD 105E

\begin{abstract}
Quality Control is a process of checking (observation) carried out by a company to ensure product quality is in accordance with predetermined standards. One of the activities of quality assurance efforts is inspection. The purpose of the inspection is to find out whether the product conforms to the specified specifications. The purpose of this research is to design a decision support system application to improve Quality Check at PT. PAS with the Acceptance Sampling method. Acceptance Sampling is a method of determining the acceptance or rejection of the observed lot using the Military Standard 105E method, as well as describing the results of testing the Quality Check system application. The research method used in designing this system application is a research and development method. The purpose of making this application is to create a computerized quality checking system and as a decision support system that can improve decision making about product quality quickly and accurately, including the following: experienced an increase in handling the entire data process compared to manual. Checking data processing will be more effective, and the security of data is more guaranteed. The process of making reports can be done quickly, precisely and accurately. It makes it easier for admins to monitor and control the data in the database.
\end{abstract}

Keywords: Decision Support System, Quality Check, MIL STD 105E

\section{PENDAHULUAN}

Dalam proses pengendalian kualitas terdapat tahapan-tahapan yang harus dilakukan oleh quality control meliputi tahapan inspeksi dari proses awal sampai proses produk jadi agar kualitas produk yang 
dihasilkan sesuai dengan standar yang telah di tetapkan. hasil akhir setelah serangkaian analisis di lewati, meliputi beberapa disposisi produk,yaitu :

1. Released: artinya produk memenuhi persyaratan spesifikasi yang telah ditentukan.

2. Rejected : artinya produk tidak memenuhi persyaratan spesifikasi yang telah ditentukan dan produk dihancurkan.

3. Work in process : artinya produk tidak memenuhi persyaratan spesifikasi yang telah ditentukan dan dilakukan reprocess/rework.

Dalam prosesnya, pembuatan laporan dan dokumentasi dilakukan secara manual,pencatatan hasil inspeksi menggunakan form kertas yang ditulis tangan dan memungkinkan terjadinya kehilangan dokumen karena tidak memiliki backup.

Oleh karena itu, dibutuhkan aplikasi sistem pengecekan yang terkomputerisasi yang dapat digunakan sebagai penunjang keputusan dan panduan pekerjaan inspeksi yang dilakukan agar sesuai standar yang ditentukan . dengan adanya aplikasi ini sebagai sarana untuk memudahkan praktisi dilapangan dalam proses pemeriksaan dan dokumentasi pemeriksaan kualitas produk.

Kualitas merupakan upaya dari produsen untuk memenuhi kepuasan pelanggan dengan memberikan apa yang menjadi kebutuhan, ekspektasi, dan bahkan harapan dari pelanggan, dimana upaya tersebut terlihat dan terukur dari hasil akhir produk yang dihasilkan [1]. kualitas yang dipertahankan sebagai target maka akan mengeliminasi kecelakaan (zero accident) mengeliminasi kerusakan (zero defect) dan mengeliminasi keluhan (zero complaint) [2]

Dalam pengendalian kualitas (quality control) inspeksi merupakan satu elemen yang sangat penting, inspeksi diperlukan untuk memastikan kualitas produk yang dihasilkan sesuai dengan ketentuan dan standarnya sehingga kepuasan pelanggan dapat terjaga dengan baik . selain mengendalikan kualitas dan menjaga kepuasan pelanggan, inspeksi juga dapat mengurangi biaya biaya operasional, akibat buruknya kualitas produk seperti biaya pengembalian produk dari pelanggan, biaya pengerjaan ulang dalam jumlah banyak dan biaya pembuangan bahan yang tidak sesuai dengan ketentuan yang berlaku. Alat bantu pengendalian kualitas digunakan untuk mendeteksi sebab-sebab terjadinya penyimpangan diluar kendali dalam proses produksi dan cara bagaimana untuk melakukan tindakan perbaikan [4].

Sistem Penunjang Keputusan adalah suatu sistem informasi spesifik yang ditujukan untuk membantu manajemen dalam mengambil keputusan yang berkaitan dengan persoalan yang bersifat semi terstruktur. Sistem ini memiliki fasilitas untuk menghasilkan berbagai alternatif yang secara interaktif digunakan oleh pemakai [3].

Sistem basis data adalah sistem terkomputerisasi yang tujuan utamanya adalah memelihara data yang sudah diolah atau informasi dan membuat informasi tersedia saat dibutuhkan[4]. Mysql adalah sebuah perangkat lunak sistem manajemen basis data SQL atau DBMS yang multithread,multi-user [5]

XAMPP adalah salah satu aplikasi web server apache yang terintegerasi dengan mysql dan phpmyadmin . XAMPP adalah singkatan dari X,Apache Server,MySQL,PHPMyadmin,dan Phyton. huruf X didepan menandakan XAMPP bisa diinstall di berbagai operating system [6].

\section{PENELITIAN YANG RELEVAN}

Hasil penelitian yang terdahulu dapat dipakai sebagai acuan untuk melakukan penelitian selanjutnya. Meskipun ada perbedaan pada objek atau variabel yang diteliti, penelitian tersebut dapat dipakai sebagai gambaran bagi peneliti berikutnya untuk melakukan penelitian

M.Fitriyan H,Agus Salim (2011) dengan judul penelitian Pengendalian kualitas dengan metode Acceptance Sampling Menggunakan Metode Objective Matrix (OMAX) Penerapan metode acceptance sampling cukup mudah dan praktis, dan dari penelitan kelima lot yang diuji ,dapat diterima. Dhieka Avrilia Lantana (2020) dengan judul penelitian Pemanfaatan Sistem Penunjang keputusan dalam menentukan kelayakan Agroindustri jambu biji berbasis mobile Metode Perbandingan eksponensial (MPE) Penggunaan aplikasi berbasis mobile dapat sangat membantu analisis finansial secara tepat dan akurat dan tepatnya pada bidang agroindustri jambu biji. 


\section{METODE PENELITIAN}

Studi literatur yang dilakukan untuk mengerjakan studi ini terdiri dari :

1. Mempelajari item pekerjaaan qc field

2. Alur inspeksi qc field dari proses awal sampai produk jadi

3. Mempelajari standar yang mengatur kegiatan proses produksi

4. Mempelajari proses dokumentasi dan report hasil inspeksi yang sesuai standar

5. Mempelajari sistem aplikasi java netbeans

Studi lapangan dilakukan di Departement Seasoning Powder PT.PAS. diantaranya :

1. Mengidentifikasi item pemeriksaaan produk

2. Mengidentifikasi alur proses inspeksi

3. Mempelajar form dan dokumen laporan inspeksi

Pengumpulan data

1. List pekerjaan pemeriksaaan

2. Standar yang mengatur kegiatan pemeriksaan

3. Form laporan dan dokumentasi hasil inspeksi

Pengolahan data

1. melakukan pengelompokan data pekerjaan pemeriksaan

2. melakukan list pekerjaan yang harus dilakukan

3. membuat list panduan untuk pemeriksaan

4. pembuatan struktur laporan

perancangan aplikasi

1. membuat ERD flow diagram

2. perancangan interface

3. perancangan database

\section{HASIL DAN PEMBAHASAN}

\section{Metode inspeksi secara sampling (sampling inspection)}

inspeksi yang dilakukan terhadap jumlah sample tertentu dari total jumlah produk yang diproduksi pada rentang waktu tertentu.sample yang diambil pada umumnya adalah sample acak (random sample) yang mewakili keseluruhan populasi produk (umumnya berdasarkan model, tenaga kerja , mesin ataupun rentang waktu tertentu). Jika dalam inspeksi terbukti mendeteksi adanya produk cacat maka keseluruhan produk terkait akan ditolak (rejected) dan harus dilakukan pengerjaan ulang atau disortir ulang.

Sample size code letters

\begin{tabular}{|c|c|c|c|c|c|c|c|c|c|}
\hline \multirow{2}{*}{\multicolumn{3}{|c|}{$\begin{array}{l}\text { Lot size (Number of } \\
\text { ordered products) }\end{array}$}} & \multicolumn{3}{|c|}{ General inspection levels } & \multicolumn{4}{|c|}{ Special inspection levels } \\
\hline & & & \multirow{2}{*}{$\begin{array}{l}\mathrm{I} \\
\mathrm{A}\end{array}$} & \multirow{2}{*}{ II } & \multirow{2}{*}{$\frac{\text { III }}{\mathrm{B}}$} & \multirow{2}{*}{$\frac{S-1}{A}$} & \multirow{2}{*}{$\frac{\mathrm{S}-2}{\mathrm{~A}}$} & \multirow{2}{*}{$\frac{\mathrm{S}-3}{\mathrm{~A}}$} & \multirow{2}{*}{$\frac{S-4}{A}$} \\
\hline 2 & to & 8 & & & & & & & \\
\hline 9 & to & 15 & $\mathrm{~A}$ & $\mathrm{~B}$ & C & $\mathrm{A}$ & A & A & A \\
\hline 16 & to & 25 & $\mathrm{~B}$ & C & $\mathrm{D}$ & $\mathrm{A}$ & A & $\mathrm{B}$ & $\mathrm{B}$ \\
\hline 26 & to & 50 & C & $\mathrm{D}$ & $E$ & $\mathrm{~A}$ & $\mathrm{~B}$ & $\mathrm{~B}$ & $\mathrm{C}$ \\
\hline 51 & to & 90 & C & $E$ & $\mathrm{~F}$ & $\mathrm{~B}$ & $\mathrm{~B}$ & C & $\mathrm{C}$ \\
\hline 91 & to & 150 & $\mathrm{D}$ & $\mathrm{F}$ & G & $\mathrm{B}$ & $\mathrm{B}$ & C & $\mathrm{D}$ \\
\hline 151 & to & 280 & $E$ & G & $\mathrm{H}$ & $B$ & C & D & $E$ \\
\hline 281 & to & 500 & $\mathrm{~F}$ & $\mathrm{H}$ & $J$ & $\mathrm{~B}$ & C & D & $E$ \\
\hline 501 & to & 1,200 & $G$ & $J$ & $K$ & C & C & $E$ & $F$ \\
\hline 1,201 & to & 3,200 & $\mathrm{H}$ & $K$ & L & $\mathrm{C}$ & D & $E$ & $G$ \\
\hline 3,201 & to & 10,000 & $J$ & $\mathrm{~L}$ & $\mathrm{M}$ & C & D & $\mathrm{F}$ & $G$ \\
\hline 10,001 & to & 35,000 & $K$ & $M$ & $N$ & C & D & $F$ & $\mathrm{H}$ \\
\hline 35,001 & to & 150,000 & $\mathrm{~L}$ & $N$ & $\mathrm{P}$ & $\mathrm{D}$ & $E$ & $G$ & $J$ \\
\hline 150,001 & to & 500,000 & $M$ & $\mathrm{P}$ & $Q$ & $\mathrm{D}$ & $E$ & $G$ & $J$ \\
\hline 500,001 & and & over & $\mathrm{N}$ & $Q$ & $\mathrm{R}$ & $\mathrm{D}$ & $E$ & $\mathrm{H}$ & $K$ \\
\hline
\end{tabular}

Gambar 1. Sample size code letters 


\section{Metode Military Standart 105E}

AQL adalah tingkat kualitas terendah (minimum) bagi proses produksi yang dianggap dapat diterima sebagai rata-rata proses. Penggunaan AQL bukanlah sebagai spesifikasi bagi produk atau sebagai target dari proses produksi, namun sebagai standar yang digunakan untuk menilai kualitas suatu lot.

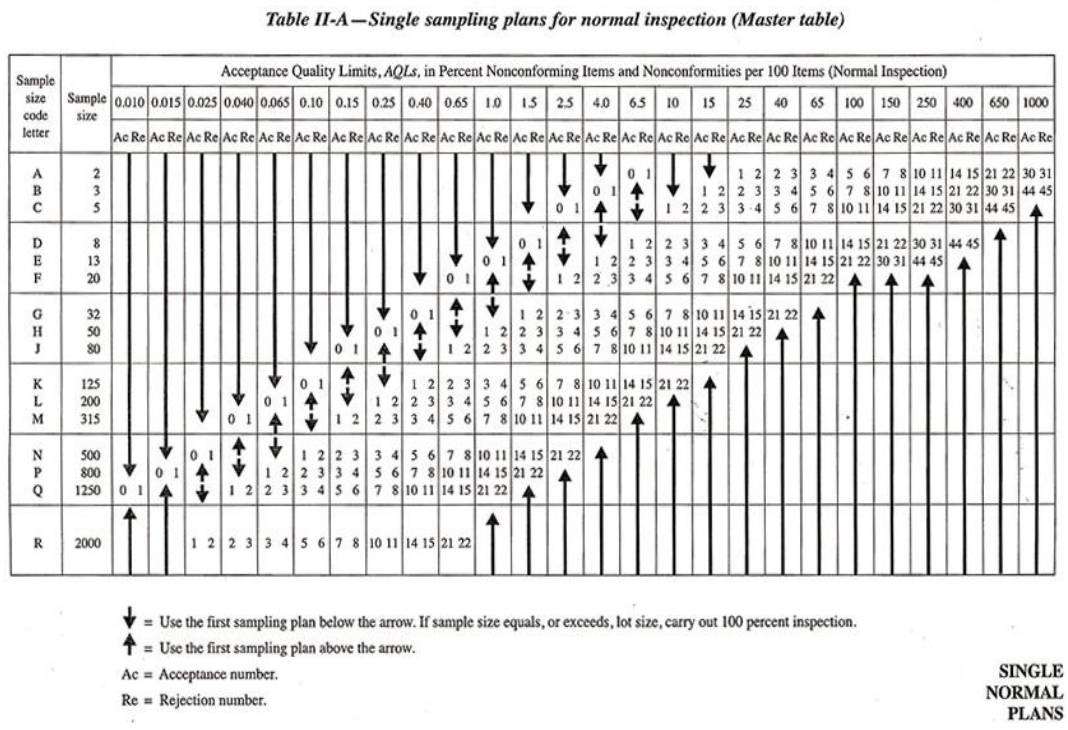

Gambar 2. Table AQL

Tingkatan AQL

Klasifikasi cacat produk

1) Critical : cacat kritis mungkin mengakibatkan kondisi berbahaya atau tidak aman menggunakan atau mempertahankan produk.

2) Major : cacat besar tidak mempengaruhi keamanan produk tetapi mempengaruhi kinerja produk.

3) Minor : cacat kecil tidak akan mempengaruhi penggunaan normal dari produk , biasanya merupakan hasil pengerjaan yang kurang memuaskan.

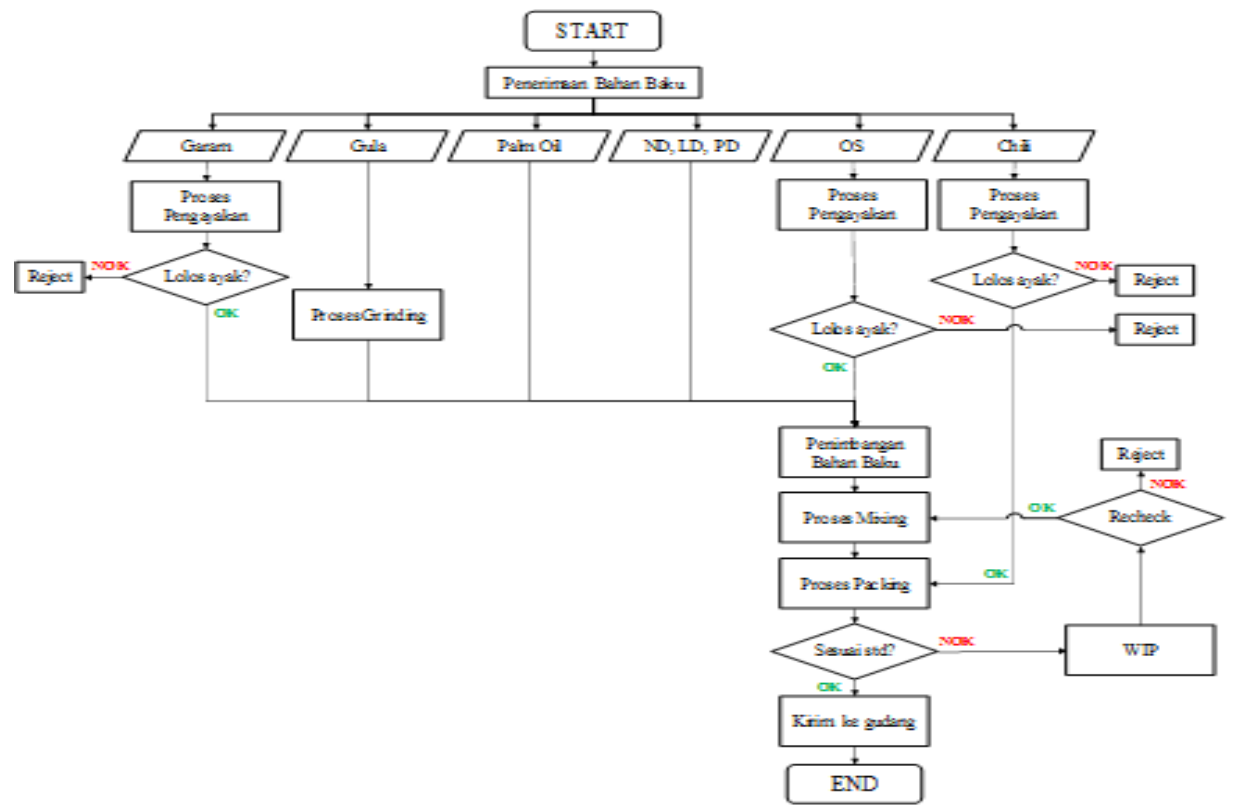

Gambar 3. Flowchart proses produksi 
Langkah pembuatan sistem sampling military standar :

a) Tentukan parameter yang mau diperiksa beserta resikonya

b) Menentukan ukuran lot

c) Menentukan AQL-nya : bisa berdasarkan kategori resiko atau kesepakatan dengan supplier (untuk bahan baku )

d) Menetukan jumlah sampel dengan cara:

Menentukan tingkat pengawasan / inspection level : tingkat pengawasan akan menentukan jumlah sampel yang harus diambil dalam satu lot.

Kategori Produk cacat

\begin{tabular}{|c|c|c|c|c|c|c|c|c|}
\hline \multirow{3}{*}{ Lot Size } & \multirow{3}{*}{\begin{tabular}{|c|} 
Spesial Inspection \\
S-3 \\
\end{tabular}} & \multirow{3}{*}{ Sample Quantity } & \multirow{2}{*}{\multicolumn{2}{|c|}{$\begin{array}{l}\text { AQL } 1.0 \\
\text { Critical }\end{array}$}} & \multirow{2}{*}{\multicolumn{2}{|c|}{$\begin{array}{l}\text { AQL } 6.5 \\
\text { Mayor } \\
\end{array}$}} & \multirow{2}{*}{\multicolumn{2}{|c|}{$\begin{array}{l}\text { AQL } 10 \\
\text { Minor } \\
\end{array}$}} \\
\hline & & & & & & & & \\
\hline & & & $A C$ & RE & $\mathrm{AC}$ & RE & $\mathrm{AC}$ & RE \\
\hline 2 to 8 & A & 2 & 0 & 0 & 0 & 1 & 0 & 0 \\
\hline 9 to 15 & A & 2 & 0 & 0 & 0 & 1 & 0 & 0 \\
\hline 16 to 25 & $B$ & 3 & 0 & 0 & 0 & 1 & 0 & 0 \\
\hline 26 to 50 & B & 3 & 0 & 0 & 0 & 1 & 0 & 0 \\
\hline 51 to 90 & $\mathrm{C}$ & 5 & 0 & 0 & 0 & 1 & 1 & 2 \\
\hline 91 to 150 & c & 5 & 0 & 0 & 0 & 1 & 1 & 2 \\
\hline 151 to 280 & D & 8 & 0 & 0 & 1 & 2 & 2 & 3 \\
\hline 281 to 500 & D & 8 & 0 & 0 & 1 & 2 & 2 & 3 \\
\hline 501 to 1,200 & $\mathrm{E}$ & 13 & 0 & 1 & 2 & 3 & 3 & 4 \\
\hline 1,201 to 3,200 & E & 13 & 0 & 1 & 2 & 3 & 3 & 4 \\
\hline 3,201 to 10,000 & $F$ & 20 & 0 & 1 & 3 & 4 & 5 & 6 \\
\hline 10,001 to 35,000 & $\mathrm{~F}$ & 20 & 0 & 1 & 3 & 4 & 5 & 6 \\
\hline 35,001 to 150,000 & G & 32 & 0 & 1 & 5 & 6 & 7 & 8 \\
\hline 150,001 to 500,000 & G & 32 & 0 & 1 & 5 & 6 & 7 & 8 \\
\hline 500,001 and over & $\mathrm{H}$ & 50 & 1 & 2 & 7 & 8 & 10 & 11 \\
\hline \multicolumn{9}{|c|}{ Kategori Produk Cacat } \\
\hline \multicolumn{2}{|c|}{ Critical } & \multicolumn{3}{|c|}{ Mayor } & \multicolumn{4}{|c|}{ Minor } \\
\hline \multicolumn{2}{|c|}{ Powder Kosong } & \multicolumn{3}{|c|}{ Gembos } & \multicolumn{4}{|c|}{ Potongan Tidak Simetris } \\
\hline \multicolumn{2}{|c|}{ Chili Kosong } & \multicolumn{3}{|c|}{ Gencet } & \multicolumn{4}{|c|}{ Inner Missprint } \\
\hline \multicolumn{2}{|c|}{ Salah Rasa } & \multicolumn{3}{|c|}{ Inner Delaminasi } & \multicolumn{4}{|c|}{ Over/under weight } \\
\hline \multicolumn{2}{|c|}{ Salah Inner/Kemasan } & & & & \multicolumn{4}{|c|}{ Garnish campur Powder } \\
\hline
\end{tabular}

Gambar 4. Kategori cacat produk

Form pemeriksaan

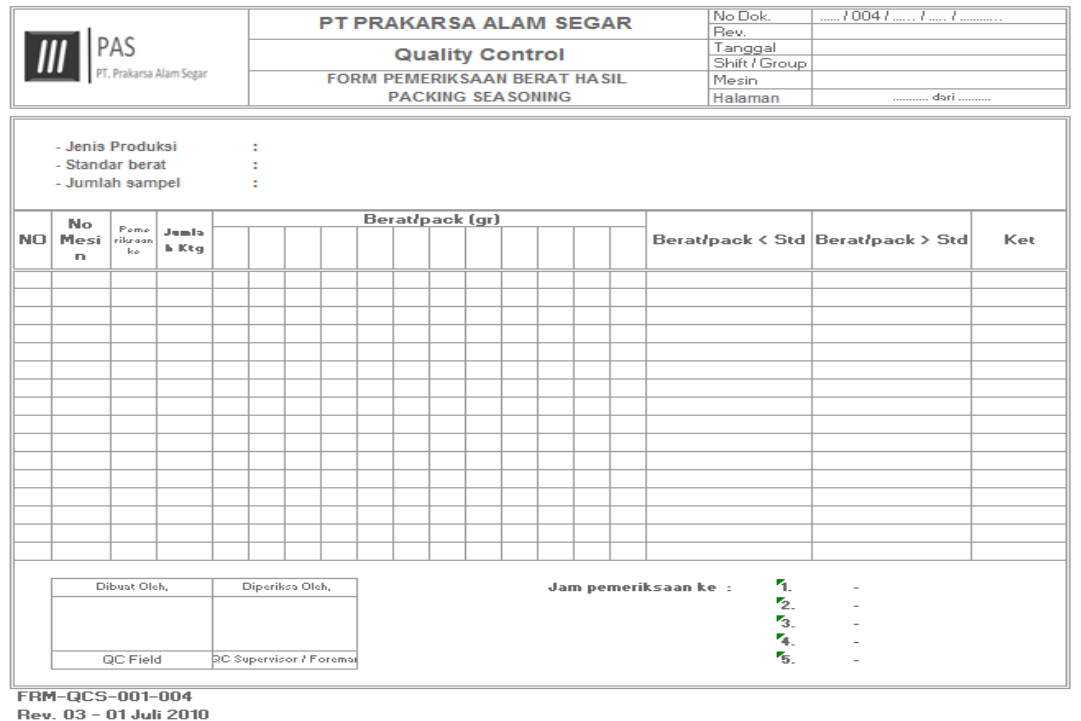

Gambar 5. Form Pemeriksaan Manual 
JRKT (Jurnal Rekayasa Komputasi Terapan)

Vol 01 No 04 Tahun 2021

\section{Tampilan layar}

1. Menu Login

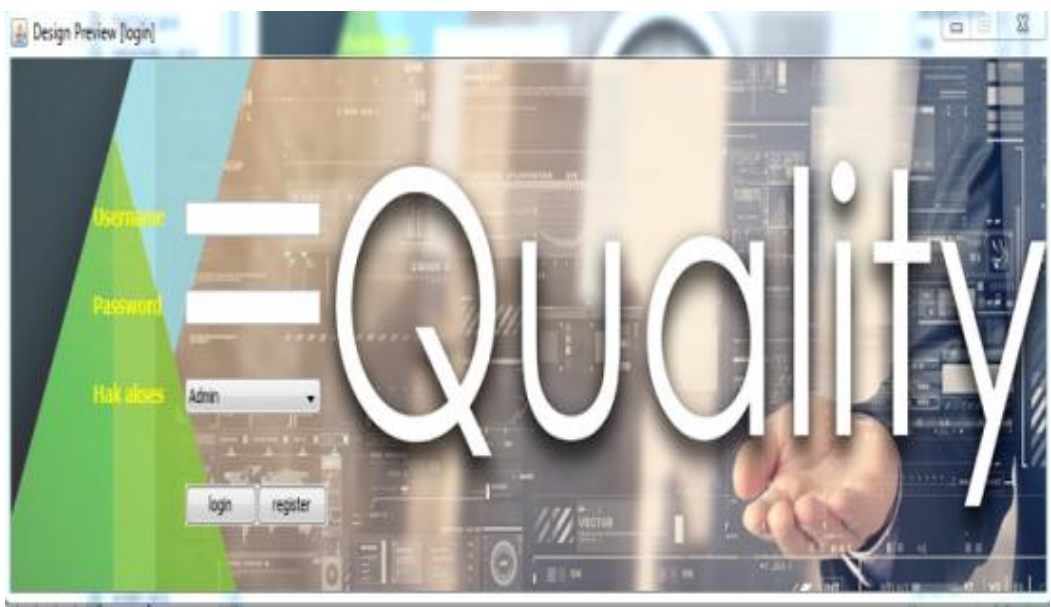

Gambar 6. Menu login

2. Menu Utama

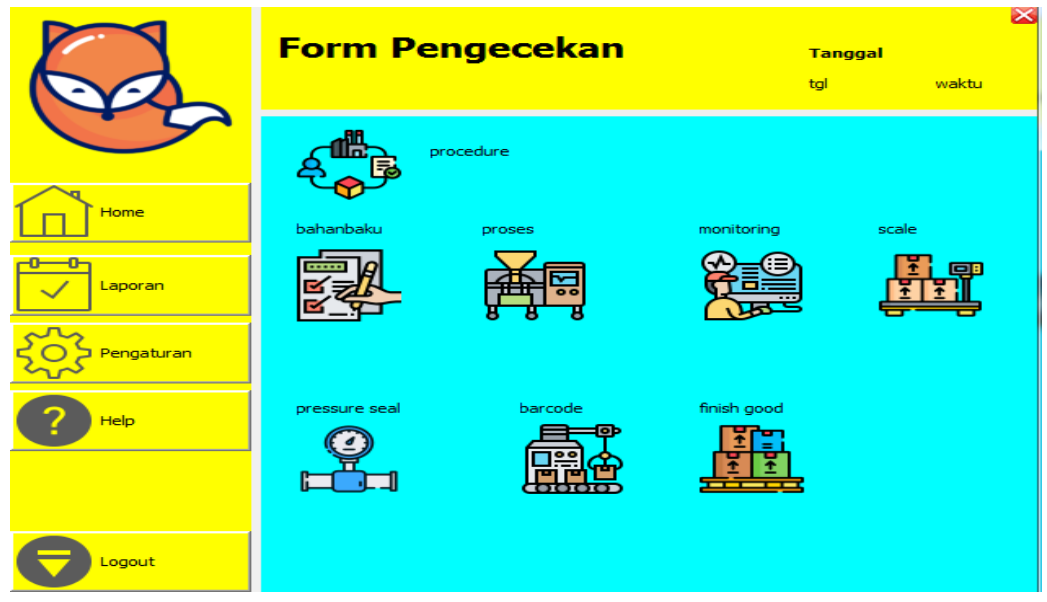

Gambar 7. Menu utama

\section{Menu Proses}

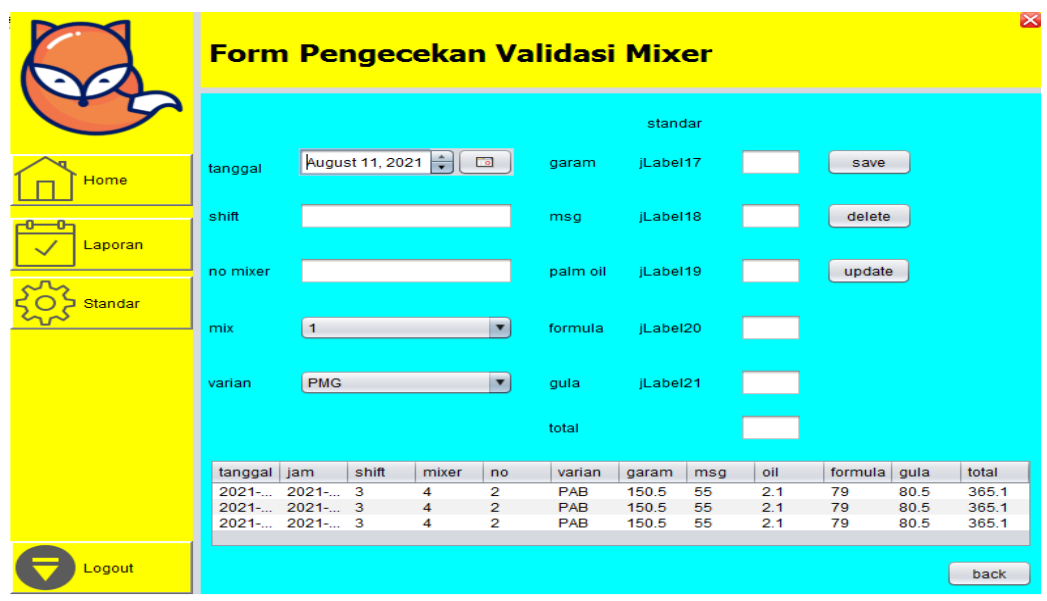

Gambar 8. Menu proses 
JRKT (Jurnal Rekayasa Komputasi Terapan)

Vol 01 No 04 Tahun 2021

e-ISSN : 2776-5873

\section{Menu bahan baku}

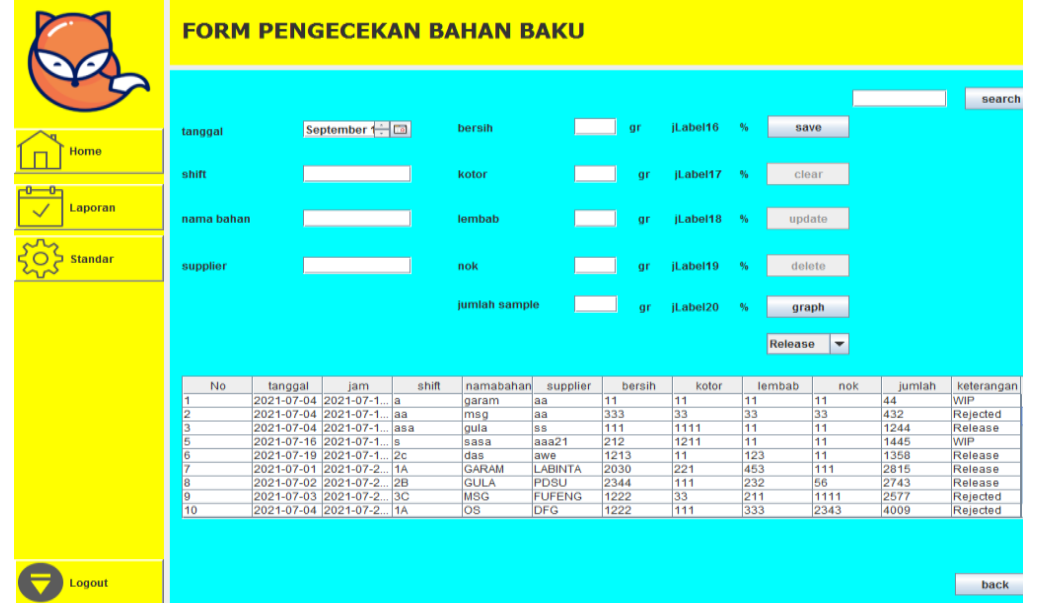

Gambar 9. Menu bahan baku

\section{Menu Scale}

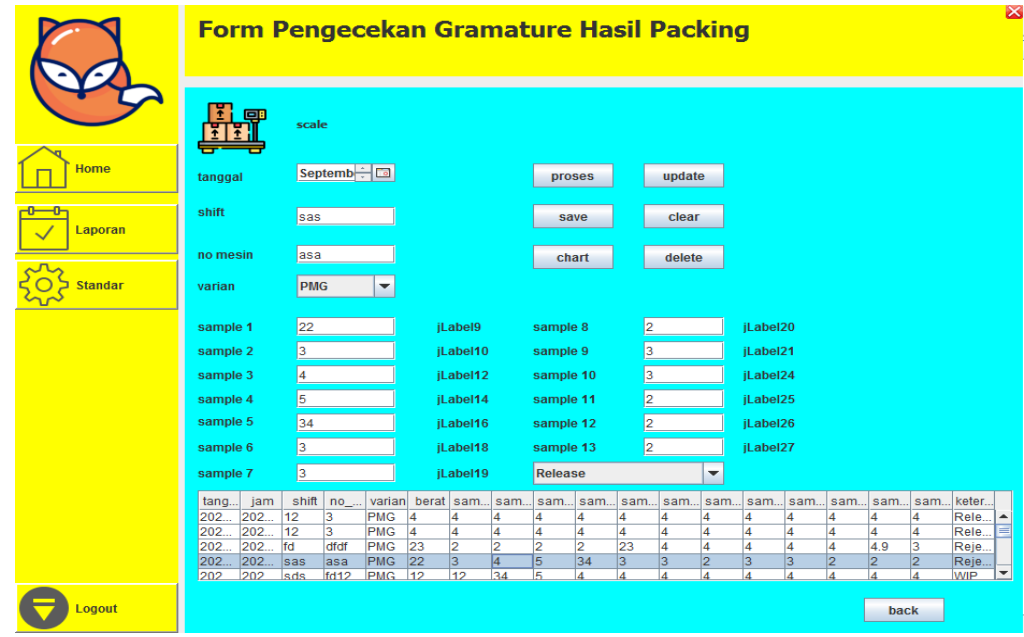

6. Menu Cetak Laporan

Gambar 10. Menu Scale

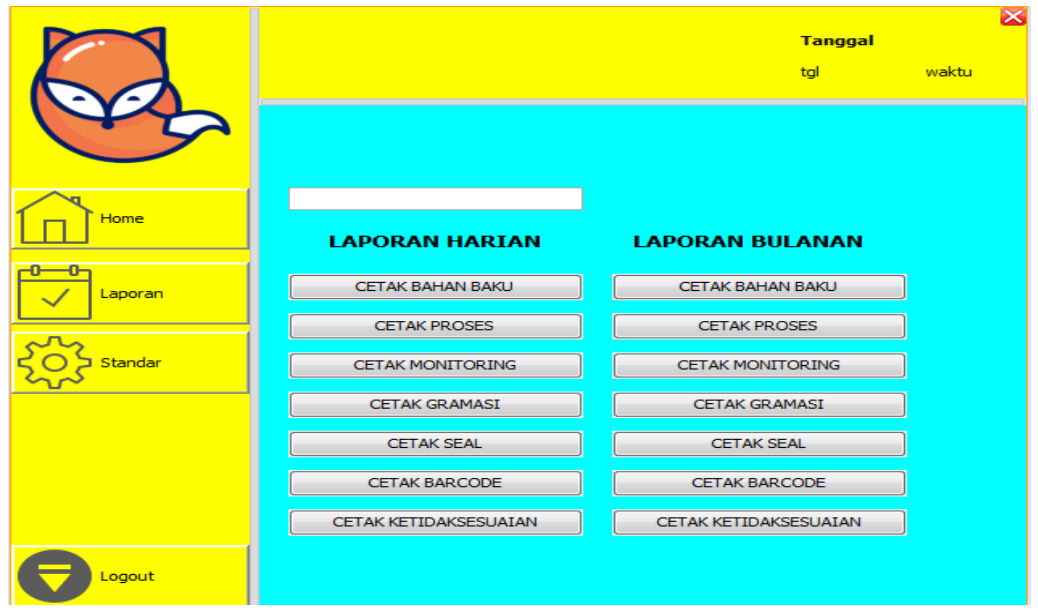

Gambar 11. Cetak laporan 
JRKT (Jurnal Rekayasa Komputasi Terapan)

Vol 01 No 04 Tahun 2021

\section{Laporan Bahan Baku}

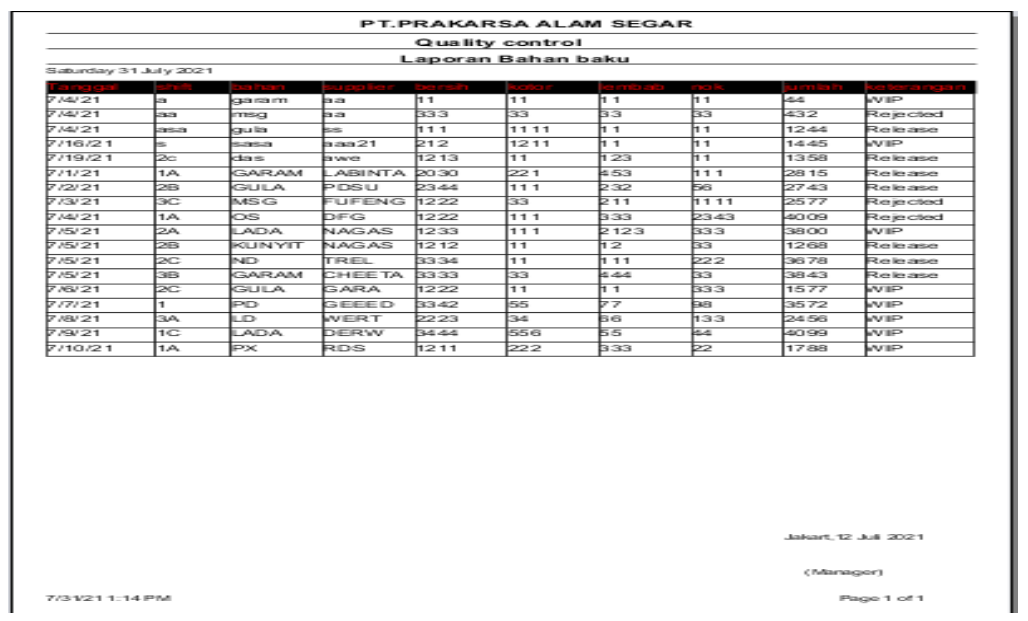

Gambar 12. Laporan bahan baku

\section{Laporan Scale}

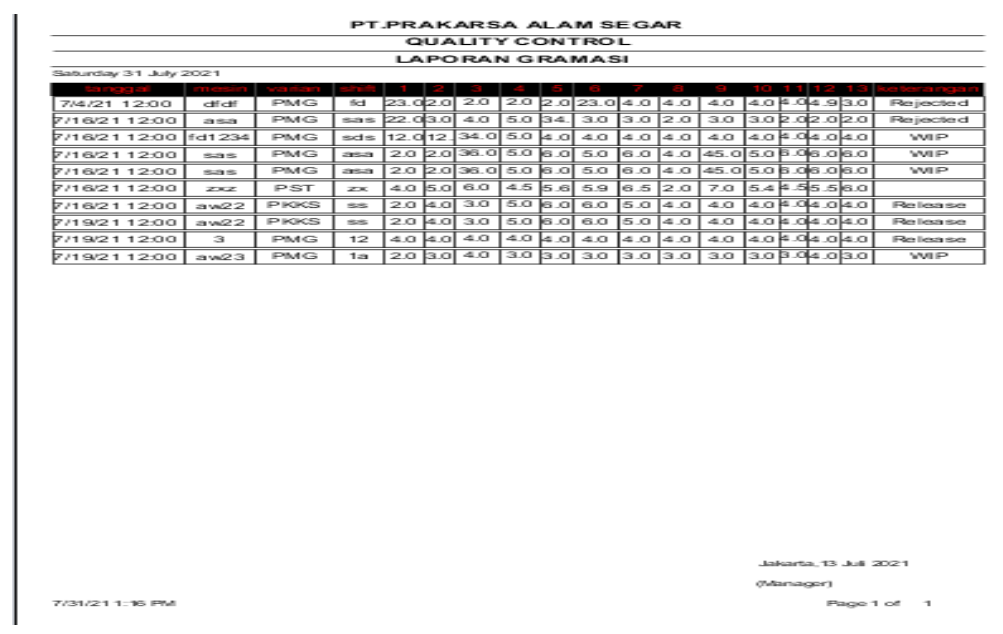

Gambar 13. Laporan scale

\section{SIMPULAN}

Berdasarkan hasil penelitian dan perancangan aplikasi ini, penulis dapat mengambil beberapa simpulan antara lain :

Aplikasi Sistem penunjang keputusan Quality check berhasil di implementasikan dengan baik.

Penginputan hasil pengecekan kualitas melalui Aplikasi Sistem penunjang keputusan Quality check menjadi lebih cepat dan tepat karena adanya data yg tersistematis.

Penyajian laporan pengecekan kualitas melalui Aplikasi Sistem penunjang keputusan Quality check menjadi lebih cepat,dan efisien dalam pencarian data traceability produk.

Aplikasi Sistem penunjang keputusan Quality check dapat memberikan disposisi produk secara cepat sesuai dengan metode Acceptance Sampling dengan menyajikan ketepatan data yang akurat.

\section{DAFTAR PUSTAKA}

[1] Dadan, \& Developers, K. (2015). Membuat Cms Multifitur. Elex Media Komputindo.

[2] Fitri, R. (2020). PEMROGRAMAN BASIS DATA MENGGUNAKAN MYSQL. Poliban Press. 
JRKT (Jurnal Rekayasa Komputasi Terapan)

Vol 01 No 04 Tahun 2021

e-ISSN : 2776-5873

[3] Latif, L., Jamil, M., \& Abbas, S. (2018). Buku Ajar : Sistem Pendukung Keputusan Teori Dan Implementasi. Deepublish.

[4] Riadi, M. (2020). Pengertian, Tujuan, Alat Bantu dan Langkah Pengendalian Kualitas. 22 February. https://www.kajianpustaka.com/2020/02/pengertian-tujuan-alat-bantu-dan-langkah-pengendaliankualitas.html

[5] Shalahudin, M., Rosa, A. . (2013). Rekayasa Perangkat Lunak: Terstruktur dan Berorientasi Objek. Informatika Bandung.

[6] Tannady, H. (2015). Pengendalian Kualitas. Yogyakarta Graha ilmu.

[7] Walujo, D. ., Koesdijati, T., \& Utomo, Y. (2020). Pengendalin Kualitas. Scopindo. 